\title{
Which factors have an association to the Quality of Life (QoL) of people with acquired Spinal Cord Injury (SCI)? A cross-sectional explorative observational study
}

\author{
Christian Sturm iD ${ }^{1 凶}$, Christoph M. Gutenbrunner ${ }^{1}$, Christoph Egen ${ }^{1}$, Veronika Geng (iD ${ }^{2}$, Christina Lemhöfer ${ }^{3}$, Yorck B. Kalke ${ }^{4}$, \\ Christoph Korallus ${ }^{1}$, Roland Thietje ${ }^{5}$, Thomas Liebscher ${ }^{6}{ }^{6}$, Rainer Abel ${ }^{7}$ and Andrea Bökel ${ }^{1}$
}

(C) The Author(s) 2021

STUDY DESIGN: Cross-sectional explorative observational study.

OBJECTIVES: To identify factors which have an association to the self-perceived Quality of Life (QoL) for persons with acquired spinal cord injury (SCI).

SETTING: Eight specialized SCl-centers in Germany. The GerSCl survey is the German part of the International Spinal Cord Injury Survey (InSCl).

METHODS: Self-disclosure questionnaire, created from the InSCl group, translated and adapted for Germany. The questionnaire collects a very broad range of data and, and due to its design as a self-report, is particularly suitable for the analysis on QoL. Because of the content, which is binding for all participating states, it allows a direct comparability of the results. Included in Germany were 1479 persons with acquired $\mathrm{SCl}$ aged 18 years and older.

RESULTS: Various factors were identified with high associations to QoL, including changeable and unchangeable ones, such as those of particular importance: pain, sleep problems, sexual dysfunction, age, and time since onset of $\mathrm{SCl}$. Some results confirmed reports of previous studies, others were surprising.

CONCLUSION: this study provides an important basis for the planned analysis of the InSCl participating countries in the 6 WHO regions. Germany was able to contribute the largest study population. The concrete study design of InSCl allows us to directly compare data and helps us to improve ourselves within the framework of a "learning health system". Medical measures can be orientated towards the found results, in order to ensure the best possible care and support by the therapeutic team, individually adapted to the person, place of residence and impairment.

Spinal Cord (2021) 59:925-932; https://doi.org/10.1038/s41393-021-00663-z

\section{INTRODUCTION}

\section{Current knowledge about Quality of Life with SCI}

The life expectancy of patients after $\mathrm{SCl}$ has increased significantly almost everywhere in the world due to better acute medical care, although there are still large international differences [1]. For this very reason, a good acute and rehabilitative care including lifelong treatment under consideration of the quality of life are becoming increasingly important.

While economic evaluations typically embrace health maximization as the maximization objective, using quality-adjusted life years, there is increasing interest in measuring capability well-being and subjective well-being for informing policy decision-makers [2].

In recent years, there have been a large amount of studies that have looked at, among other things, the impact on the quality of life of people with $\mathrm{SCl}$. Only a few of the more newer ones can be named here as examples that attempt to reflect the state of knowledge. Factors that seem to have a particularly high association are pain and spasticity [3-6], as well as bladder and bowel function [7-9]. Sexual dysfunction also seems to have an association to QoL $[6,10,11]$.

Studys and already meta-analysis showed the high impact to QoL of the psychological aspects. Greater acceptance of $\mathrm{SCl}$, life satisfaction, level of depression and anxiety have associations to QoL [6, 12-16]. A great influence on the mental status seems to have the participation in social life $[6,16]$.

Healthy $\mathrm{SCl}$ individuals tend to have better QoL measures and secondary health issues after $\mathrm{SCl}$ are affecting QoL and social participation [17]. Older studies, but also very recent ones, confirm that the quality of life of adults with chronic $\mathrm{SCl}$ was lower compared with reference populations $[6,18]$.

In the past, it was already regretted that there was no single definition of Quality of Life that everyone agreed upon, largely due to the breadth of literature that addressed this topic and the varying definitions used in studies [19]. This, too, makes it difficult to compare results between populations or different states.

\footnotetext{
${ }^{1}$ Department of Rehabilitation Medicine, Hannover Medical School, Hanover, Germany. ${ }^{2}$ Manfred-Sauer-Foundation, Lobbach, Germany. ${ }^{3}$ Institute for Physiotherapy, University Hospital Jena, Jena, Germany. ${ }^{4}$ RKU - University and Rehabilitation Clinics Ulm, Ulm, Germany. ${ }^{5}$ Center for spinal injuries, Trauma Hospital Hamburg, Hamburg, Germany. ${ }^{6}$ Treatment Centre for Spinal Cord Injuries, Trauma Hospital Berlin, Berlin, Germany. ${ }^{7} \mathrm{SCI}$ Unit, Klinikum Bayreuth GmbH, Bayreuth, Germany. ${ }^{\circledR}$ email: sturm.christian@mh-hannover.de
} 
International research projects such as $\mathrm{InSCl}$ could help to ensure that there is a uniform definition at some time.

\section{International background}

Both the United Nations (UN) and the World Health Organization (WHO) demand the collection of internationally comparable data on the living and care situation of people with disabilities [20]. Consequently, the International Spinal Cord Injury Survey (InSCI) was launched, headed by the International Spinal Cord Society (ISCoS) and the International Society of Physical and Rehabilitation Medicine (ISPRM), within the framework of the WHO Collaboration Plan and the coordination of Swiss Paraplegic Research (SPF). The aim of the InSCI is for health systems to learn from each other through the comparison of results of the 22 participating countries in all $6 \mathrm{WHO}$ regions. The outcomes should also help to develop recommendations for decision-makers in politics and health care [21]. Furthermore, reliable national data are also required to ensure optimal care and supply [22]. Germany is one of the participating countries to collect these requested data to compare within InSCl. In Germany the project is called "German Spinal Cord Injury Survey (GerSCl)".

One special advantage of the InSCl survey is, that the persons concerned are asked about their point of view and their perceived situation. Therefore, this data collection is particularly suitable for the analysis of the factors potentially influencing perceived Quality of Life (QoL).

\section{Special aspects of this study}

One of the first results of the GerSCl study was that, for persons with $\mathrm{SCl}$, QoL decreased with increasing experience of barriers. Some of these aspects have already been highlighted by our study group [23], but it became clear that for this important topic of QoL a specific analysis of the different probably influencing factors was necessary. Therefore, we wanted to look at the different factors individually and try to put them into a clinical context.

In literature, a number of comprehensive questionnaires to assess QoL are available. They are based on diverse constructs of QoL and focus mainly on health-related performance in daily life. Another approach refers to a more general feeling of the subjective perception of life quality. Of course, subjective perception has multiple dimensions but also is related to the individual's values and life goals. For pragmatic reasons and because the use of complex and extended questionnaires in our study would have led to be not user-friendly we decided to use a commonly used single question to get a rough estimate of subjective level of QoL. The evaluation of separate components and the differentiation between various constructs of functioning should be the subject of future studies. The specific aims of this study were: (i) to describe the level of Quality of Life in the German study population and (ii) to identify and describe the probability of influence on covariates of Quality of Life. (iii) to provide a basis for international comparison within $\ln \mathrm{SCl}$.

\section{Methods}

The German Spinal Cord Injury Survey (GerSCl) data set, as the German part of InSCl, served as the basis for the study. The used questionnaire was developed centrally by the $\mathrm{InSCl}$ study group and is thus binding for all $\mathrm{InSCI}$ participating countries. It has been shown, that the successful implementation of the InSCl survey enables the comparison of the situation of individuals with $\mathrm{SCl}$ in different regions around the world and constitutes a crucial starting point for an international learning experience [24]. GerSCl was implemented in 2017 and was conducted by the Department of Rehabilitation Medicine at Hannover Medical School.

\section{Inclusion criteria:}

- Presence of acquired SCI (traumatic or non-traumatic)

- Age $\geq 18$ years
- Completed post-acute rehabilitation: 12 months after the onset of the spinal cord lesion

- Current place of residence: Germany, language competence: German

\section{Exclusion criteria:}

\section{- Congenital $\mathrm{SCl}$ or neurodegenerative diseases}

From the database of the eight participating specialized $\mathrm{SCl}$ centers, 5,598 potential

participants were identified. They were treated at least once in one of these specialized SCl clinics inpatient or outpatient. They received an invitation letter and the questionnaire, which they could answer in paper form or electronically. After the exclusion of questionnaires that failed to satisfy the inclusion criteria, the available participant data declined by $n=79$. Some were excluded due to aborted online questionnaires $(n=56)$, received duplicate questionnaires $(n=2)$ and $>30 \%$ of missing values $(n=138)$. 1479 questionnaires were considered for data evaluation [25].

The potential influence of various factors on QoL were studied using measurements of association.

\section{Survey instruments}

Measuring quality of life (WHOQoL-BREF). The WHOQoL-BREF is an instrument for recording subjective QoL. It is based on the definition of QoL, as the perception of one's own life situation in the context of respective culture and value systems, as well as in relation to individual goals, expectations, and interests. We use the term QoL to refer to the perceived, purely subjective experience of the participants, in order to reflect their individual perspective in this study. We relate this statement to perceived barriers and enabling factors. The WHOQoL-BREF questionnaire consists of 26 items that focus on several dimensions, such as physical wellbeing, psychological well-being, social relationships, and environment [26]. Six items were used from the WHOQoL-BREF in the $\mathrm{GerSCl}$ questionnaire. These items were predetermined by the $\mathrm{InSCl}$ study group. Since there is no reliable sum score of this question selection given by the InSCl team, we chose the overall QoL assessment as the primary target criterion. However, regarding this study, the item which was used for associations as the main parameter was, "How would you rate your quality of life in the last 30 days?", which were rated on a scale with five ratings from "very poor" to "very good". Since not the complete WHOQoL-Bref was used in this questionnaire, we were able to create the WHOQoL-Bref global domain score with the first and second question using a scale transformation (0-100). This scale transformed global domain values were then compared to the general population in the year 2000 according to Angermeyer et al. [27]. Unfortunately, no matched and more recent comparison sample is available from Germany.

\section{Covariates}

The selection of the covariates within the framework of the $\operatorname{lnSCl}$ questionnaire was made based on the literature reports described in the introduction and expert discussion within the $\mathrm{GerSCl}$ team about possible additional relevant factors. In order to analyze for associations, sociodemographic data and lesion characteristics were used, including age, gender, relationship status, level of injury (paraplegia vs tetraplegia), injury severity (complete vs incomplete), time since injury, etiology (traumatic vs nontraumatic), satisfaction with community health services (satisfied vs not satisfied), difficulties gaining medical aids (no vs yes), employment status (unemployed vs employed), education level (low vs high), net household income (under average vs over average) and health conditions (no vs yes: sleep problems, bowel 


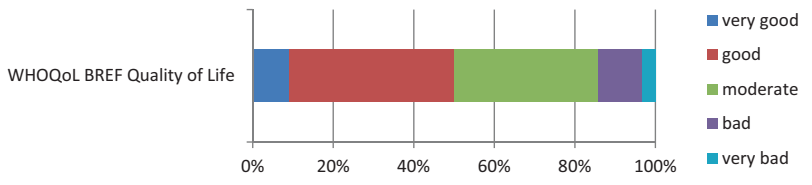

Fig. 1 Comparison of the QoL of the study population compared to the norm sample. Response frequencies to the question: "How would you rate your quality of life in the last 30 days?".

dysfunction, sexual dysfunction, contractures, decubitus, urinary bladder function, bladder infection, spasticity, respiratory problems, injuries due to sensory disorders, circulatory problems or circulatory disorders, dysreflexia, orthostatic hypotension, diabetes mellitus, periarticular ossification), and pain (no to mild, and moderate to severe).

The five rating categories of the WHOQoL-Bref were dichotomized into "0", which corresponded with "very bad", "bad" and "mediocre" and "1", which corresponded with "well" and "very good". The pain-scale with rating categories 0 to 10 was convertes in a dummy variable according to Ledowski et al. in $0-3=$ no to mild pain and $4-10=$ moderate to severe pain [28]. Education status was converted in a dummy variable as $1=$ no school leaving certificate, primary school certificate, lower secondary graduation, secondary school graduation, and $2=$ advanced technical college entrance qualification, Abitur (general university entrance qualification). Satisfaction with community health service was converted in a dummy variable as $1=$ "very satisfied", "satisfied" and $2=$ "neither" or, "unsatisfied", "very unsatisfied". Net household income was categorized into $1=$ "less than $981 €$, 982-1345 €, 1346-1660 €, 1661-1990 €, 1991-2339 €, 2340-2732 $€, 2337-3195 €$ ", and $2=$ "3196-3819 $€, 3820-4837 €$, more than $4838 €^{\prime \prime}$ according to average monthly net income per private household in Germany [29]. Problematic health conditions during the last three months were rated on a 5 point Likert scale from "not problematic" until "extremely problematic". In this analysis, we dichotomized the scale in $0=$ "no problem" and $1=$ "a little problematic" till "extremely problematic".

\section{Statistical analysis}

Sociodemographic data and $\mathrm{SCl}$ characteristics were presented as percentages or means with standard deviation (SD). The key focus of this study was the QoL of people with SCl in Germany. WHOQoL-Bref frequencies were presented as percentages. Only the data from participants with less than $30 \%$ missing values were included in the statistical analysis.

To analyze associations between QoL covariates, associations using Eta and Cramers'V were calculated.

The determinants of QoL covariates associated with the perception of a high quality of life were assessed using multivariable logistic regression and estimated odds ratios (OR) with a 95\% Confidence interval $(\mathrm{Cl})$. Variables were included if they showed significant associations to QoL, which were all variables except marital status.

The proportion of missing values was less than $5 \%$, therefore no imputation of missing values has been performed.

Results were considered statistically significant if $p$ values were less than 0.05 . Statistical analyses were performed with SPSS IBM 26.0.

\section{RESULTS}

The average age of the respondents was 55.3 years (SD: 14.6). The range was from 19 to 90 years. 51,2\%; stated a paraplegia; $48,8 \%$ a tetraplegia. Further details of socio-demographic and lesion characteristics of study participants are available elsewhere [23].

Most respondents answered the question "How would you rate your quality of life in the last 30 days?" with "good" (41\%) to

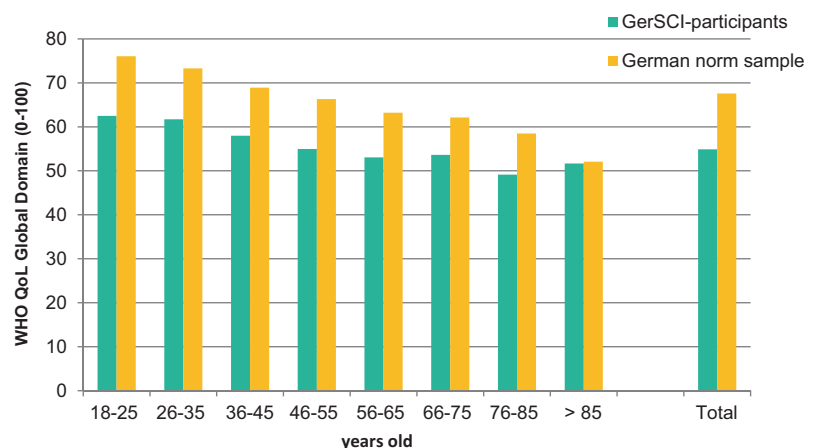

Fig. 2 Results of factors associated with a high QoL. Comparison of the QoL of the study population with the norm sample description.

"moderate" (36\%). A smaller proportion described it as "bad" (11\%) or "very bad" (3.3\%). A "very good" quality of life was reported by $9.0 \%$ (Fig. 1).

Fig. 2 shows the comparison of the QoL of the study population in relation to the available norm sample [27]. With regard to the age groups, it can be seen that the values of the norm sample are higher than the values of the study population in all age groups. In the age group $>85$ years they are almost the same.

For almost all values selected from clinical experience and literature research, the association analysis showed a high significance with the development of QoL of $p<0.05$, and most of them were even $p<0.001$ (Tables 1 and 2).

Due to this high levels of significance of most of the chosen factors, it is important to consider the effect size in order to assess the relevance of the factors. The largest effect size with Cramers' V above 0.30 (Interpretation of Cramér's $\mathrm{V}$ according to Cohen: small $=0.10$; medium $=0.30$; large $=0.50$ ) were for pain, sleep problems, and sexual dysfunction. Even this does not say anything statistically accurate about the absolute level of association.

A logistic regression analysis shows that both the model as a whole (chi-square $(27)=249.695, p<0.001$ ) and some of the individual coefficients of the variables are significant. The Rsquare after Nagelkerke is 0.403 , which explains $40.3 \%$ of the regression model.

The results of the logistic regression are displayed in Table 3. A higher relative probability of experiencing a good QoL is linked to people who are satisfied with their community health services (OR $=1.730 ; p=0.013)$, those who have no difficulties in gaining medical aids $(\mathrm{OR}=2.176 ; \quad p<0.001)$, who have no bowel dysfunction (OR $=1.774 ; p=0.023)$, no sexual dysfunction (OR $=1.969 ; p=0.027)$, no contractures ( $\mathrm{OR}=1.626 ; p=0.032$ ), no to mild pain $(\mathrm{OR}=3.289 ; p<0.001)$ and no diabetes mellitus $(\mathrm{OR}=$ 2.013; $p=0.039$ ). Those who are unemployed ( $\mathrm{OR}=0.562 ; p=$ 0.004 ) have a higher relative probability of not experiencing a high QoL compared to employed participants. Converted from the data it can be concluded that with every year of life, the relative probability of a good QoL decreases by $3.1 \%$ and increases by $2.4 \%$ with each additional year of occurrence of $\mathrm{SCl}$.

\section{DISCUSSION}

The study showed that there are some physical impairments that seem to have particularly high influence on QoL. Particularly noteworthy are pain, contractures, bowel and sexual dysfunction. Some social factors also show high associations with perceived QoL, such as employment, being satisfied with their community health services and having no difficulties in gaining medical aids. The results largely confirm trends seen earlier, but some results also contradict the previous findings. We will focus on the factors that showed the highest effect sizes. 
Table 1. Results of contingency analysis with nominal data using Cramers'V.

\begin{tabular}{|c|c|c|c|}
\hline $\begin{array}{l}\text { Independent variable correlated } \\
\text { with QoL }\end{array}$ & $n$ & $p$ & Cramers' V \\
\hline Gender & 1409 & 0.001 & 0.085 \\
\hline Lesion height & 1376 & 0.027 & 0.060 \\
\hline Completeness of lesion & 1402 & 0.008 & 0.070 \\
\hline $\mathrm{SCl}$ cause & 1397 & $<0.001$ & 0.131 \\
\hline Education level & 1405 & 0.010 & 0.069 \\
\hline Net household income & 1282 & $<0.001$ & 0.209 \\
\hline Relationship status & 1428 & 0.262 & 0.030 \\
\hline Employed in working age & 1054 & $<0.001$ & 0.260 \\
\hline $\begin{array}{l}\text { Satisfaction community health } \\
\text { services }\end{array}$ & 1405 & $<0.001$ & 0.140 \\
\hline Difficulties gaining medical aids & 1388 & $<0.001$ & 0.124 \\
\hline Sleep problems & 1406 & $<0.001$ & 0.306 \\
\hline Bowel dysfunction & 1401 & $<0.001$ & 0.289 \\
\hline Urinary tract infections & 1389 & $<0.001$ & 0.146 \\
\hline Urinary bladder dysfunction & 1389 & $<0.001$ & 0.203 \\
\hline Sexual dysfunction & 1304 & $<0.001$ & 0.306 \\
\hline Contractures & 1376 & $<0.001$ & 0.258 \\
\hline Spasticity & 1411 & $<0.001$ & 0.153 \\
\hline Decubitus & 1396 & $<0.001$ & 0.165 \\
\hline Respiratory problems & 1388 & $<0.001$ & 0.219 \\
\hline Injuries due to sensory disorders & 1388 & $<0.001$ & 0.154 \\
\hline $\begin{array}{l}\text { Circulatory problems or circulatory } \\
\text { disorders }\end{array}$ & 1403 & $<0.001$ & 0.203 \\
\hline Dysreflexia & 1400 & $<0.001$ & 0.230 \\
\hline Orthostatic hypotension & 1386 & $<0.001$ & 0.220 \\
\hline Pain & 1404 & $<0.001$ & 0.358 \\
\hline Joint and muscle pain & 1409 & $<0.001$ & 0.297 \\
\hline Diabetes mellitus & 1386 & $<0.001$ & 0.148 \\
\hline Periarticular ossification & 1339 & $<0.001$ & 0.129 \\
\hline
\end{tabular}

$P$ values $<0.05$ are marked in bold.

Table 2. Results of contingency analysis with metric data using Eta.

\begin{tabular}{|c|c|c|c|}
\hline $\begin{array}{l}\text { Independent variable correlated } \\
\text { with QoL }\end{array}$ & $n$ & $p$ & Eta \\
\hline Age & 1426 & $<0.001$ & 0.168 \\
\hline Time since injury & 1402 & 0.007 & 0.118 \\
\hline
\end{tabular}

$P$ values $<0.05$ are marked in bold.

Impairment factors, like lesion height and completeness of lesion, were of lower significance in the association to reported QoL in this survey. A comparison of the literature showed that contradictory statements have already been made in this regard in the past. It has already been reported that, as in our case, there were no relevant association [30], others reported more indirect associations to QoL via physical functioning [31, 32]. Other findings showed that the level of injury in people with $\mathrm{SCl}$ had a high impact on their QoL, suggesting that these people need adaptive and compensatory equipment to improve their QoL $[33,34]$. Maybe the influence on QoL depends on the technical possibilities for rehabilitation and support in the country of origin of the studies, as these results were reported from Iran and Bangladesh. But also in Canada with high level medical support the injury severity indicated via the physical functioning influence on QoL [32]. Other studys found now significant influence directly to QoL and also referred to indirect effects via physical function and participation [31].

The meaning of the relationship status still seems unclear in relation to other results so far. With $p=0.262$ there was no significant association to the overall QoL. However, there were contradictory trends on this in earlier reports about the impact on QoL. In a survey of people with $\mathrm{SCl}$ for global meaning, the participants named relationship status as one of the five most important factors [35]. Results from Greece showed married life as associated with higher QoL levels ( $p=0.006)$ [36]. In Canada it was reported, that being married positively affected life satisfaction [32]. It can be assumed that there are parallels between global meaning, life satisfaction and QoL. However, comparability is limited because the terms describe different nuances in the selfassessment of personal status. In another comparison of 6 different countries, there was no association of the relationship status with QoL [31].

The largest effect size with Cramers' $V(>0,3)$ showed up for pain, sleep problems, and sexual dysfunction. We also want to go into more detail about some of the other factors that showed high effect sizes in the analysis.

Pain has already shown its high influence on QoL in the literature. One of the studies demonstrated that despite all previous efforts, the presence, complexity, and stability of pain symptoms were refractory to treatment and produced lower QoL ratings in persons with chronic $\mathrm{SCl}$ [37]. Several types of pain typically occur in $\mathrm{SCl}$, with central neuropathic pain being a frequent and difficult to manage occurrence [38]. The cyclical relationship of musculoskeletal pain, reduced activity, and maladaptive psychological factors allude to the interdependence of factors, supporting the multidisciplinary approach to care [39]. More precise causes of still high pain levels cannot be deduced from this self-report questionnaire

Sleep problems are a known problem since years. For example in an analysis from Switzerland in 2011 individuals with SCI reported more sleep problems compared to the general Swiss population. This study suggests that clinical screening for sleep issues targeting high-risk groups is needed to reduce the large prevalence of non-treatment in individuals with $\mathrm{SCl}$ [40]. The results of the survey do not show us whether the problems are more about falling asleep or staying asleep. However, the causes of sleep disturbances can be various. Psychological problems can cause them just as much as pain, digestive disorders, or sensations in the extremities.

Sexual dysfunction has a high association to QoL and is particularly interesting from a clinical point of view, since it is already known from another analysis of our data that although sexual dysfunction often exist they are nevertheless rarely under medical treatment, or that patients do not seek medical advice for this issue [41]. There may be an issue where QoL can be practically improved through medical assistance.

The logistic regression results are clinically interesting, because they show the probability of experiencing a high QoL in relation to this variables. In addition to the mentioned factors above, there were some more variables worth a consideration.

Bowel dysfunction and diabetes mellitus are challenges for treatment by health professionals. While the influence of bowel dysfunctions is obvious, diabetes is more likely to affect QoL through secondary diseases such as polyneuropathy, or the need for medication such as insulin injections. Unfortunately, multimorbidity is common, with $59.1 \%$ of individuals with $\mathrm{SCl}$ [32].

The influence of existing contractures on QoL is important to bear in mind. Targeted and multimodal therapy with physiotherapeutic measures, pharmaceutical support and, if necessary surgical release may be required. 
Table 3. Logistic regression for factors associated with the perception of a high QoL.

Variables

$\mathrm{Chi}^{2}(27)=249,695, p<0.001$

Nagelkerkes $R^{2}=0.403$

Age

Gender (male vs female)

Para vs tetra

Complete vs incomplete

Time since injury

Aetiology (traumatic vs non-traumatic)

Satisfaction community health services (satisfied vs not satisfied)

Difficulties gaining medical aids (no vs yes)

Employment status (unemployed vs employed)

Educational level (low vs high)

Net household income (under average vs over average)

Sleep problems (no vs yes)

Bowel dysfunction (no vs yes)

Sexual dysfunction (no vs yes)

Contractures (no vs yes)

Decubitus (no vs yes)

Pain (no/mild vs moderate/severe pain)

Urinary bladder dysfunction (no vs yes)

Bladder infection (no vs yes)

Spasticity (no vs yes)

Respiratory problems (no vs yes)

Injuries due to sensory disorders (no vs yes)

Circulatory problems or circulatory disorders (no vs yes)

Dysreflexia (no vs yes)

Orthostatic hypotension (no vs yes)

Diabetes mellitus (no vs yes)

Periarticular ossification (no vs yes)

The reference category was the last one, e.g., female gender is the reference category

$O R$ odds ratio, $\mathrm{Cl}$ confidence interval.
95\% confidence interval

\begin{tabular}{|c|c|c|c|}
\hline$p$ & OR & Lower value & Upper value \\
\hline 001 & 969 & 951 & 987 \\
\hline 192 & 1.342 & 862 & 2.088 \\
\hline 787 & 946 & 629 & 1.420 \\
\hline 647 & 904 & 586 & 1.394 \\
\hline 013 & 1.024 & 1.005 & 1.043 \\
\hline 237 & 1.336 & 827 & 2.160 \\
\hline 013 & 1.730 & 1.124 & 2.663 \\
\hline 000 & 2.167 & 1.461 & 3.216 \\
\hline 004 & 562 & 0.380 & 830 \\
\hline 675 & 918 & 615 & 1.370 \\
\hline 070 & 656 & 416 & 1.036 \\
\hline 394 & 1.215 & 776 & 1.903 \\
\hline 023 & 1.774 & 1.083 & 2.907 \\
\hline 027 & 1.969 & 1.081 & 3.588 \\
\hline 032 & 1.626 & 1.042 & 2.539 \\
\hline 101 & 1.425 & 0.934 & 2.175 \\
\hline 000 & 3.289 & 2.200 & 4.919 \\
\hline 939 & 1.016 & 0.669 & 1.544 \\
\hline 376 & 0.820 & 529 & 1.272 \\
\hline 767 & 1.076 & 662 & 1.749 \\
\hline 389 & 1.207 & 787 & 1.852 \\
\hline 703 & 1.087 & 708 & 1.668 \\
\hline 154 & 721 & 460 & 1.131 \\
\hline 214 & 1.304 & 858 & 1.983 \\
\hline 187 & 1.334 & 870 & 2.047 \\
\hline 039 & 2.013 & 1.038 & 3.904 \\
\hline 374 & 1.271 & 749 & 2.158 \\
\hline
\end{tabular}

Being satisfied with their community health services and having no difficulties in gaining medical aids showed a high odds ratio. This confirms the high value for people with $\mathrm{SCl}$ of a good rehabilitation system and generous technical support. The importance has been reported before: technology plays a critical role in promoting well-being, activity, and participation for individuals with $\mathrm{SCl}$. This ranges from lighter wheelchairs to new software, which makes computer interfaces adaptive [42]. Perhaps the importance of the health system and the technical support is also the reason why there are so many differences in QoL between countries. For instance in a study with data from Australia, Brazil, Canada, Israel, South Africa, and the United States of America, analysis of variance showed that living in Brazil was a significant predictor of lower QoL. The differences between the countries could not be explained by differences in demographic and lesionrelated characteristics. The results point to the relevance of reintegration of people with $\mathrm{SCl}$ into the workforce [31]. Many factors could account for this differences, one could be varying degrees of technical support in the different countries.

As unemployment has been shown to be a risk factor for low QoL, vocational support measures are also an important option and should be implemented early in the rehabilitation strategy. Further discussion on this point has already been published by our study group [43]. However, work can also have a negative influence if it is overstrained. Cross-sectional data from 386 employed men and women with $\mathrm{SCl}$ from the Netherlands, Switzerland, Denmark, and Norway were analyzed and work stress and low job control was linked to decreased general QoL [44].

The results regarding age and time since the onset of $\mathrm{SCl}$ were largely consistent with previous studies. Declining QoL coincides in the normal population with increasing age. That time elapsed since the onset of SCl mostly means a higher QoL is usually attributed to a higher acceptance and better adaptation to the functional impairments due to acquired $\mathrm{SCl}[31,34,36,45]$. However, there have also been results where QoL did not deteriorate with increasing age. In these studies, it was considered that the positive aspects of getting used to $\mathrm{SCl}$ outweighed the general trend of decreasing QoL with age [39].

\section{Strengths}

A major advantage of this analysis is the questionnaire, which asks very broadly about many aspects of daily life. It was developed centrally by the $\ln \mathrm{SCl}$ study group and is thus binding for all $\ln \mathrm{SCl}$ participating countries. This allows a direct comparison between countries of all different $\mathrm{WHO}$ regions. This can facilitate the 
discussion of differences and promote improvements in the context of a "learning health system".

Another advantage is the largest study population $(n=1479)$ of all participating countries within $\mathrm{InSCl}$.

\section{LIMITATIONS}

The recruiting strategy included possible selection bias because all invited persons were treated at least once in one of the specialized $\mathrm{SCl}$ clinics. It is possible (and even probable), that the supply situation of persons with $\mathrm{SCl}$ who have not been treated in such a center is even worse. The response rate of $32.6 \%$ was acceptable but not very high compared to some other surveys. This could be caused by the extensive questionnaire. Another selection bias is possible because answering the questionnaire itself is a challenge for people's mental ability and motor activity. This may have excluded people who were severely impaired and had no personal assistance to fill in. Regarding the interpretation, it must be taken into account that QoL was assessed only on the basis of one question about the perceived overall situation of QoL and this only according to the last 30 days. Seasonal deviations for example are not recorded with it. In the regression model about $40 \%$ could be explained. This is statistically a good value, but it also shows us that we cannot yet fully explain many associations and, above all, interactions of variables.

The dichotomisation of the variables could possibly lead to a distortion of the results.

\section{CONCLUSION}

The results of this study provide many indications, but these must certainly be examined in more detail in further studies to determine the cause and options for improvement. However, multifarious factors have been identified that show a high association with the perceived and reported general QoL. From a medical point of view, these are particularly important, as they are modifiable and can lead to practical consequences for possible adjustments of support or medical measures. The importance of a good health care system with adapted rehabilitation and specific support is emphasized by the described complaints and needs. However,the measures must also be adjusted to the financial and infrastructural possibilities of the region in question. It remains important to work closely with each individual person with $\mathrm{SCl}$, since only as a team with doctors, therapists, and technicians, supported by social or political measures, can the goal of providing the best possible care be achieved. Only then can barriers be broken down, impairments reduced, and the Quality of Life noticeably improved.

\section{DATA AVAILABILITY}

The original data are available on request to Mrs. Bökel, Hannover Medical School, Germany or at the InSCI Study Center at the Swiss Paraplegic Center, Nottwil, Switzerland.

\section{REFERENCES}

1. Thietje R. Epidemiologie, Ätiologie und Mortalität bei Querschnittlähmung. Neuroreha. 2016;08:105-9. https://doi.org/10.1055/s-0042-112079

2. Engel L, Bryan S, Noonan VK, Whitehurst DGT. Using path analysis to investigate the relationships between standardized instruments that measure health-related quality of life, capability wellbeing and subjective wellbeing: An application in the context of spinal cord injury. Soc Sci Med. 2018;213:154-64. https://doi.org/ 10.1016/j.socscimed.2018.07.041

3. Andresen SR, Biering-Sørensen F, Hagen EM, Nielsen JF, Bach FW, Finnerup NB. Pain, spasticity and quality of life in individuals with traumatic spinal cord injury in Denmark. Spinal Cord. 2016;54:973-9. https://doi.org/10.1038/sc.2016.46

4. Nagoshi N, Kaneko S, Fujiyoshi K, Takemitsu M, Yagi M, lizuka S, et al. Characteristics of neuropathic pain and its relationship with quality of life in 72 patients with spinal cord injury. Spinal Cord. 2016;54:656-61. https://doi.org/ 10.1038/sc.2015.210

5. Burke D, Lennon O, Fullen BM. Quality of life after spinal cord injury: the impact of pain. Eur J Pain. 2018;22:1662-72. https://doi.org/10.1002/ejp.1248

6. Chang F, Xie H, Zhang Q, Sun M, Yang Y, Chen G, et al. Quality of life of adults with chronic spinal cord injury in mainland china: A cross-sectional study. J Rehabil Med. 2020. https://doi.org/10.2340/16501977-2689.

7. Nevedal A, Kratz AL, Tate DG. Women's experiences of living with neurogenic bladder and bowel after spinal cord injury: life controlled by bladder and bowel. Disabil Rehabil. 2016;38:573-81. https://doi.org/10.3109/ 09638288.2015.1049378

8. Theisen KM, Mann R, Roth JD, Pariser JJ, Stoffel JT, Lenherr SM, et al. Frequency of patient-reported UTIs is associated with poor quality of life after spinal cord injury: a prospective observational study. Spinal Cord 2020. https://doi.org/ 10.1038/s41393-020-0481-z.

9. Rofi'i AYAB, Maria R, Masfuri. Quality of life after spinal cord injury: an overview. Enferm Clin. 2019;29 Suppl 2:1-4. https://doi.org/10.1016/j.enfcli.2019.05.001. Suppl 2.

10. Merghati-Khoei E, Emami-Razavi SH, Bakhtiyari M, Lamyian M, Hajmirzaei S, TonTab Haghighi S, et al. Spinal cord injury and women's sexual life: case-control study. Spinal Cord. 2017;55:269-73. https://doi.org/10.1038/sc.2016.106

11. Stoffel JT, van der Aa F, Wittmann D, Yande S, Elliott S. Fertility and sexuality in the spinal cord injury patient. World J Urol. 2018;36:1577-85. https://doi.org/ 10.1007/s00345-018-2347-y

12. van Leeuwen CMC, Kraaijeveld S, Lindeman E, Post MWM. Associations between psychological factors and quality of life ratings in persons with spinal cord injury: a systematic review. Spinal Cord. 2012;50:174-87. https://doi.org/10.1038/ sc. 2011.120

13. Peterson MD, Kamdar N, Chiodo A, Tate DG Psychological morbidity and chronic disease among adults with traumatic spinal cord injuries: a longitudinal cohort study of privately insured beneficiaries. Mayo Clin Proc. 2020. https://doi.org/ 10.1016/j.mayocp.2019.11.029.

14. Eaton R, Jones K, Duff J. Cognitive appraisals and emotional status following a spinal cord injury in post-acute rehabilitation. Spinal Cord. 2018;56:1151-7. https://doi.org/10.1038/s41393-018-0151-6

15. Aaby A, Ravn SL, Kasch H, Andersen TE. The associations of acceptance with quality of life and mental health following spinal cord injury: a systematic review. Spinal Cord. 2020;58:130-48. https://doi.org/10.1038/s41393-019-0379-9

16. Müller R, Landmann G, Béchir M, Hinrichs T, Arnet U, Jordan X, et al. Chronic pain, depression and quality of life in individuals with spinal cord injury: mediating role of participation. J Rehabil Med. 2017;49:489-96. https://doi.org/10.2340/ 16501977-2241

17. Frontera JE, Mollett P. Aging with spinal cord injury: an update. Phys Med Rehabil Clin N Am. 2017;28:821-8. https://doi.org/10.1016/j.pmr.2017.06.013

18. Lidal IB, Veenstra M, Hjeltnes N, Biering-Sørensen F. Health-related quality of life in persons with long-standing spinal cord injury. Spinal Cord. 2008;46:710-5. https://doi.org/10.1038/sc.2008.17

19. Charlifue S, Post MW, Biering-Sørensen F, Catz A, Dijkers M, Geyh S, et al. International spinal cord injury quality of life basic data set. Spinal Cord. 2012;50:672-5. https://doi.org/10.1038/sc.2012.27

20. Bundesministerium für Arbeit und Soziales. Zweiter Teilhabebericht der Bundesregierung über die Lebenslagen von Menschen mit Beeinträchtigungen. 2016. https://www.bmas.de/SharedDocs/Downloads/DE/PDF-Publikationen/ a125-16-teilhabebericht.pdf;jsessionid=FC8AE05EC6FAFA6CB9F5ACB5C08794 F0?__blob=publicationFile\&v=9. Accessed 12 Aug 2020.

21. Gross-Hemmi MH, Post MWM, Ehrmann C, Fekete C, Hasnan N, Middleton JW, et al. Study Protocol of the International Spinal Cord Injury (InSCI) Community Survey. Am J Phys Med Rehabil. 2017;96:S23-S34. https://doi.org/10.1097/ PHM.0000000000000647

22. Bickenbach J, Officer A, Shakespeare T, Groote P von. International Perspectives on Spinal Cord Injury. Geneva: World Health Organization; 2013.

23. Bökel A, Dierks M-L, Gutenbrunner C, Weidner N, Geng V, Kalke Y-B, et al. Perceived environmental barriers for people with spinal cord injury in Germany and their influence on quality of life. J Rehabil Med. 2020;52:jrm00090 https://doi.org/ 10.2340/16501977-2717

24. Fekete C, Brach M, Ehrmann C, Post MWM, Stucki G Cohort Profile of the International Spinal Cord Injury Community Survey Implemented in 22 Countries. Arch Phys Med Rehabil. 2020. https://doi.org/10.1016/j.apmr.2020.01.022.

25. Bökel A, Blumenthal M, Egen C, Geng V, Gutenbrunner C Querschnittlähmung in Deutschland: Eine nationale Befragung (German Spinal Cord Injury Survey (GerSCl) Teilprojekt des Spinal Cord Injury Community Survey (InSCI)): Medizinische Hochschule Hannover Bibliothek.

26. Development of the World Health Organization WHOQOL-BREF quality of life assessment. The WHOQOL Group. Psychol Med 1998;28:551-8. https://doi.org/ $10.1017 /$ S0033291798006667. 
27. MC Angermeyer, R Kilian, $\mathrm{H}$ Matschinger. WHOQOL-100 and WHOQOL-BREF. Handbook of the German Version of the WHO Instrument to Assess Quality of life: Handbook of the German Version of the WHO Instrument to Assess Quality of life; 2000.

28. Ledowski T, Bromilow J, Paech MJ, Storm H, Hacking R, Schug SA. Monitoring of skin conductance to assess postoperative pain intensity. $\mathrm{Br} J$ Anaesth 2006;97:862-5. https://doi.org/10.1093/bja/ael280.

29. Rudnicka J Statistiken zu Haushalten in Deutschland. 2020.

30. Middleton J, Tran Y, Craig A. Relationship between quality of life and self-efficacy in persons with spinal cord injuries. Arch Phys Med Rehabil. 2007;88:1643-8. https://doi.org/10.1016/j.apmr.2007.09.001.

31. Geyh S, Ballert C, Sinnott A, Charlifue S, Catz A, D'Andrea Greve JM, et al. Quality of life after spinal cord injury: a comparison across six countries. Spinal Cord. 2013;51:322-6. https://doi.org/10.1038/sc.2012.128

32. Rivers CS, Fallah N, Noonan VK, Whitehurst DG, Schwartz CE, Finkelstein JA, et al Health conditions: effect on function, health-related quality of life, and life satisfaction after traumatic spinal cord injury. a prospective observational registry cohort study. Arch Phys Med Rehabil. 2018;99:443-51. https://doi.org/10.1016/j. apmr.2017.06.012

33. Khadije Khazaeli, Effat Hoseini, Amir Hosein Nasir, Mousa Amarloui, Mohammad Kazem Ganji, editor. Relationship between level of injury and quality of life in spinal cord injury (SCI) patients: Payesh. 2019; 18: 45-51.

34. Ahmed N, Quadir MM, Rahman MA, Alamgir H. Community integration and life satisfaction among individuals with spinal cord injury living in the community after receiving institutional care in Bangladesh. Disabil Rehabil. 2018;40:1033-40. https://doi.org/10.1080/09638288.2017.1283713

35. Littooij E, Widdershoven GAM, Stolwijk-Swüste JM, Doodeman S, Leget CJW, Dekker J. Global meaning in people with spinal cord injury: content and changes. J Spinal Cord Med. 2016;39:197-205. https://doi.org/10.1179/2045772314Y. 0000000290

36. Tzanos I-A, Kyriakides A, Gkintoni E, Panagiotopoulos E. Quality of life (QoL) of people with spinal cord injury (SCI) in Western Greece. RS. 2019;4:7 https://doi. org/10.11648/j.rs.20190401.12

37. Gibbs K, Beaufort A, Stein A, Leung TM, Sison C, Bloom O. Assessment of pain symptoms and quality of life using the International Spinal Cord Injury Data Sets in persons with chronic spinal cord injury. Spinal Cord Ser Cases. 2019;5:13 https://doi.org/10.1038/s41394-019-0178-8

38. Siddall PJ, Middleton JW. Spinal cord injury-induced pain: mechanisms and treatments. Pain Manag. 2015;5:493-507. https://doi.org/10.2217/pmt.15.47

39. Finley MA, Euiler E Association of musculoskeletal pain, fear-avoidance factors, and quality of life in active manual wheelchair users with $\mathrm{SCl}$ : a pilot study. J Spinal Cord Med. 2019:1-8. https://doi.org/10.1080/10790268.2019.1565717.

40. Buzzell A, Chamberlain JD, Schubert M, Mueller G, Berlowitz DJ, Brinkhof MWG Perceived sleep problems after spinal cord injury: Results from a communitybased survey in Switzerland. J Spinal Cord Med. 2020:1-10. https://doi.org/ 10.1080/10790268.2019.1710938.

41. Bökel A, Egen C, Gutenbrunner C, Weidner N, Moosburger J, Abel F-R, et al. Querschnittlähmung in Deutschland-eine Befragung zur Lebens- und Versorgungssituation von Menschen mit Querschnittlähmung. [Spinal Cord Injury in Germany - a Survey on the Living and Care Situation of People with Spinal Cord Injury]. Rehabilitation (Stuttg). 2020;59:205-13. https://doi.org/10.1055/a-10715935

42. Cooper RA, Cooper R. Quality-of-life technology for people with spinal cord injuries. Phys Med Rehabil Clin N Am. 2010;21:1-13. https://doi.org/10.1016/j. pmr.2009.07.004

43. Sturm C, Bökel A, Korallus C, Geng V, Kalke YB, Abel R, et al.. Promoting factors and barriers to participation in working life for people with spinal cord injury. JMET-D-20-00142R1. https://doi.org/10.1186/s12995-020-00288-7.

44. Fekete C, Wahrendorf M, Reinhardt JD, Post MWM, Siegrist J. Work stress and quality of life in persons with disabilities from four European countries: the case of spinal cord injury. Qual Life Res. 2014;23:1661-71. https://doi.org/10.1007/ s11136-013-0610-7

45. Geyh S, Kunz S, Müller R, Peter C. Describing functioning and health after spinal cord injury in the light of psychological-personal factors. J Rehabil Med. 2016;48:219-34. https://doi.org/10.2340/16501977-2027

\section{ACKNOWLEDGEMENTS}

This study is based on data from the International Spinal Cord Injury (InSCI) Community Survey, providing the evidence for the Learning Health System for Spinal Cord Injury (LHS-SCl, see Am J Phys Med Rehabil 2017;96(Suppl): S23-S34). The LHS$\mathrm{SCl}$ is an effort to implement the recommendations described in the WHO report
International Perspectives on Spinal Cord Injury (Bickenbach J et al. Geneva: WHO Press; 2013). The members of the InSCl Steering Committee are: James Middleton (ISCoS representative; Member Scientific Committee; Australia), Julia Patrick Engkasan (ISPRM representative; Malaysia), Gerold Stucki (Chair Scientific Committee; Switzerland), Mirjam Brach (Representative Coordinating Institute; Switzerland), Jerome Bickenbach (Member Scientific Committee; Switzerland), Christine Fekete (Member Scientific Committee; Switzerland), Christine Thyrian (Representative Study Center Switzerland), Linamara Battistella (Brazil), Jianan Li (China), Brigitte Perrouin-Verbe (France), Christoph Gutenbrunner (Member Scientific Committee; Germany), Christina-Anastasia Rapidi (Greece), Luh Karunia Wahyuni (Indonesia), Mauro Zampolini (Italy), Eiichi Saitoh (Japan), Bum Suk Lee (Korea), Alvydas Juocevicius (Lithuania), Nazirah Hasnan (Malaysia), Abderrazak Hajjioui (Morocco), Marcel W.M. Post (Member Scientific Committee; The Netherlands), Johan K. Stanghelle (Norway) Piotr Tederko (Poland), Daiana Popa (Romania), Conran Joseph (South Africa), Mercè Avellanet (Spain), Michael Baumberger (Switzerland), Apichana Kovindha (Thailand) Reuben Escorpizo (Member Scientific Committee; USA). GerSCI team This study is a project of several collaborating partners. The cooperating clinics, which are members of the German-speaking Medical Society for Paraplegiology, provided the field access and sent the questionnaires. The organisation, coordination, data management and descriptive evaluation took place in the Department of Rehabilitation Medicine of Hannover Medical School. The study was carried out in collaboration with the following specialised SCl-centers: Center of spinal cord injuries and diseases / Department of Paraplegiology and Neuro-Urology, Central Hospital Bad Berka headed by Dr. med. Ines Kurze, SCI Center Median Clinic Bad Tennstedt headed by Dr. med. Helgrit Marz-Loose, Paraplegic Center of the University and Rehabilitation Clinic Ulm headed by Dr. med. Yorck-Bernhard Kalke, Medical Rehabilitation Center for Paraplegics of the Heinrich Summer Clinic in Bad Wildbad headed by Dr. med. Michael Zell, Center for Tetra- and Paraplegia of the Orthopedic Clinic Hessisch Lichtenau headed by Dr. med. Marion Saur, Center for Paraplegics of the Clinic Hohe Warte Bayreuth headed by PD Dr. med. Rainer Abel, Department of Paraplegics, University Hospital Heidelberg headed by Prof. Dr. med. Nobert Weidner and the Center for Spinal Cord Injuries of the Emergency Hospital Berlin headed by Dr. med. Andreas Niedeggen.

\section{FUNDING}

The study was funded by Manfred-Sauer-Foundation. Open Access funding enabled and organized by Projekt DEAL.

\section{AUTHOR CONTRIBUTIONS}

CS: analysed data and wrote article Andrea Bökel: led statistics, organized GerSCl. CE: organized $\mathrm{GerSCl}$. $\mathrm{CL}$ : helped with data analysis, references and review process. VG: connection to funder of the study and organized parts of the study. YBK: chief of one of the study centers, organization of recruitment and checked and corrected the article CK: organization of recruitment and checked and corrected the article RT: chief of one of the study centers, organization of recruitment and checked and corrected the article RA: chief of one of the study centers, organization of recruitment and checked and corrected the article CMG: head of GerSCI team Hanover, representative for Germany in the International Spinal Cord Injury Survey (InSCl).

\section{COMPETING INTERESTS}

The authors declare no competing interests.

\section{STATEMENT OF ETHICS}

Study was approved by the Ethics committee of the Hannover Medical School (MHH) in accordance with the Helsinki Declaration of 1975 (No. 7374), as well as the Commissioner for Data Protection at $\mathrm{MHH}$

\section{ADDITIONAL INFORMATION}

Correspondence and requests for materials should be addressed to C.S.

Reprints and permission information is available at http://www.nature.com/ reprints

Publisher's note Springer Nature remains neutral with regard to jurisdictional claims in published maps and institutional affiliations. 
Open Access This article is licensed under a Creative Commons Attribution 4.0 International License, which permits use, sharing, adaptation, distribution and reproduction in any medium or format, as long as you give appropriate credit to the original author(s) and the source, provide a link to the Creative Commons license, and indicate if changes were made. The images or other third party material in this article are included in the article's Creative Commons license, unless indicated otherwise in a credit line to the material. If material is not included in the article's Creative Commons license and your intended use is not permitted by statutory regulation or exceeds the permitted use, you will need to obtain permission directly from the copyright holder. To view a copy of this license, visit http://creativecommons. org/licenses/by/4.0/.

(c) The Author(s) 2021 